\title{
Internet e redes sociais no ambiente de trabalho: Uma análise com funcionários do setor hoteleiro da cidade de Natal (Rio Grande do Norte, Brasil)
}

\section{Internet and social media in the workplace: An analysis with employees of hotel sector in the city of Natal (Rio Grande do Norte, Brazil)}

\author{
Elizabete Varela da Silva (SILVA, E. V. da) ${ }^{*}$ e \\ Luiz Mendes Filho (MENDES FILHO, L. A.) ${ }^{* *}$
}

\begin{abstract}
RESUMO - A Tecnologia da Informação foi uma das inovações que surgiu e ganhou força com a globalização, e se faz presente em todas as partes e segmentos sociais, de diversas formas. Este trabalho tem como objetivo analisar o uso da Internet e redes sociais no ambiente de trabalho, na perspectiva dos funcionários do setor hoteleiro da cidade de Natal, Rio Grande do Norte, Brasil. Através de pesquisa quali-quantitativa, exploratória descritiva, utilizando um formulário com perguntas atinentes, foi possível abarcar questões pertinentes ao tema e através da análise de conteúdo avaliar os resultados. A coleta dos dados ocorreu entre os dias 22 de abril e 19 de maio de 2014, totalizando 52 funcionários respondentes, atingindo 9 hotéis. Constatou-se que a maioria dos funcionários estava usando e acessando Internet e redes sociais no trabalho, principalmente através de aparelhos celulares e computadores, mesmo que a empresa não liberasse o acesso a tais ferramentas. O maior acesso abrangendo as redes sociais conhecidas como Facebook e WhatsApp, e para os respondentes tal prática poderia apontar ou não danos nas atividades profissionais, dependendo de cada caso. Concluiuse que o uso da Internet e redes sociais no ambiente de trabalho era algo que já fazia parte da realidade dos funcionários que estavam atuando em hotéis na cidade de Natal e que, para tais empresas, manterem-se conectadas também às redes sociais seria uma ferramenta útil para conquistar outros clientes.
\end{abstract}

Palavras-Chave: Hotelaria; Internet; Redes Sociais; Ambiente de Trabalho.

ABSTRACT - Information Technology was one of the innovations that emerged and gained strength with globalization, and is present in all parties and social groups in various ways. This work aims to analyze the use of Internet and social media in the workplace, from the perspective of employees in the hospitality industry of the city of Natal, Rio Grande do Norte, Brazil. Through a quali-quantitative and descriptive exploratory research, using questions to cover issues relevant to the topic and through a content analysis to evaluate the results. Data collection took place between April 22 and May 19, 2014, totaling 52 respondents' employees, reaching 9 hotels. It was found that

\footnotetext{
* Formação: Graduação em Turismo (Bacharelado) pela Universidade Federal do Rio Grande do Norte (UFRN). Atividade profissional: Assistente Financeiro, Praiamar Empreendimentos Turísticos LTDA. Endereço físico para correspondência: Rua Antomar de B. Freitas, 3655 (Candelária). CEP: 59064-590, Natal/RN - Brasil. Email: elizabetevarela@hotmail.com

** Formação: Bacharelado em Ciências da Computação (UFRN), Mestrado em Engenharia da Produção (UFRN), Doutorado em Administração (Auckland University of Technology, Nova Zelândia). Atividade profissional: Professor do Programa de Pós-Graduação em Turismo (PPGTUR/UFRN) e professor do Departamento de Turismo (UFRN). Endereço físico para correspondência: Rua Antonio Farache, 1880 (Capim Macio). CEP 59082-110 - Natal/RN - Brasil. Telefone para contato: 5584 99911-5727. Email: luiz.mendesfilho@gmail.com
} 
most employees were using and accessing Internet and social media at work, mainly through cell phones and computers, even if the company would release no access to such tools. Greater access including social media known as Facebook and WhatsApp, and for respondents such practice could point or no damage in professional activities, depending on each case. It was concluded that the use of Internet and social media in the workplace was something that was already part of the reality of employees who were working in hotels in Natal and that, for such companies, remain also connected to social media would be a formidable tool to conquer other customers.

Key words: Hospitality; Internet; Social Media; Workplace. 


\section{INTRODUÇÃO}

A Tecnologia da Informação foi uma das inovações que surgiu e ganhou força com a globalização, e se faz presente em todas as partes e segmentos sociais, de diversas formas. Percebe-se que empresas estão congregando ao processo de trabalho as tecnologias. Tais tecnologias possibilitam a modernização de uma empresa, assim a mesma pode operar suas atividades com mais qualidade e oferecer um melhor atendimento ao cliente, além de permitir um sistema de informações, controle e gerenciamento que possa suscitar menos custos. Com "a chegada da Internet proporcionou um novo comportamento à sociedade" (ROBERTO, 2009, p. 38). A Internet está revolucionando o mundo dos negócios, criando novas formas de interação entre pessoas e organizações (LOBIANCO; RAMOS, 2004, p. 4). Através da Internet, passam a se proliferar as redes sociais que "tem a função de reunir diversas pessoas para interagir umas com as outras, e com isso elas trocam e compartilham informações e conteúdos (SILVA; MENDES FILHO, 2013, p. 180). A primeira rede social era conhecida como ClassMates (colegas, em inglês), desenvolvida pelo norte-americano Randy Conrads para reunir amigos da escola e faculdade (BOLETINES PANDALABS, 2008). No quadro abaixo se representa a cronologia dos principais recursos de redes sociais mais utilizadas.

QUADRO 1 - CRONOLOGIA DOS PRINCIPAIS RECURSOS DE REDE SOCIAL

\begin{tabular}{|c|c|c|c|c|c|c|}
\hline $\mathbf{1 9 9 5}$ & $\mathbf{1 9 9 7}$ & $\mathbf{2 0 0 2}$ & $\mathbf{2 0 0 3}$ & $\mathbf{2 0 0 4}$ & $\mathbf{2 0 0 5}$ & $\mathbf{2 0 0 6}$ \\
\hline Classmates & SixDegrees & Friendster & MySpace & Orkut & $\begin{array}{c}\text { Yahoo } \\
360^{\circ}\end{array}$ & Facebook \\
\hline & & Fotolog & Linkedin & & Bebo & Twitter \\
\hline & & & & & & Tuenti \\
\hline
\end{tabular}

Fonte: Adaptado de Boletines PandaLabs, 2008, p. 4.

Outro recurso existente é o WhatsApp e o Instagram, ambos cresceram rapidamente e passaram a fazer parte da rotina diária da maioria das pessoas. As inovações e ferramentas tecnológicas permitem que se possa acessar a internet e as redes sociais em qualquer lugar e a qualquer momento através de aparelhos celulares, computadores e diversos equipamentos. O que facilita a comunicação e interação das pessoas. A pesquisa denominada "Emerging Nations Embrace Internet, Mobile 
Technology” (PEW RESEARCH CENTER, 2013), realizada com 24.263 pessoas em 24 países emergentes entre o período de 2 de março de 2013 a 1 de Maio de 2013 apresentou alguns resultados sobre o uso da internet e das redes sociais em países emergentes. Dos resultados obtidos com relação ao Brasil, destaca-se que entre os brasileiros que tinham acesso à internet, $73 \%$ usavam redes sociais; $15 \%$ das pessoas tinham um smartphone e $49 \%$ usavam a internet. Ao todo, $96 \%$ dos usuários mencionaram usar as plataformas para dialogar com amigos e familiares. A faixa etária com maior parcela de uso de sites como o Facebook e o Twitter no Brasil eram os jovens de 18 a 29 anos. A menor incidência estava ocorrendo entre pessoas maiores de 50 anos, com apenas $18 \%$. Assim, observa-se que a população economicamente ativa está usufruindo dos recursos tecnológicos para comunicar-se, entreter-se e informar-se através da internet e das redes sociais, inclusive no que concerne o setor turístico, pois “a utilização de informações em meios eletrônicos no turismo é muito comum, devido o turismo possuir um grande volume de informações dinâmicas" (SILVA; MENDES FILHO, 2013, p. 179). Realmente a Internet está cada vez mais mudando a maneira com que as pessoas procuram, compartilham e consomem informação no turismo (MENDES FILHO; CORREA; MANGUEIRA, 2015). Conforme Mendes Filho e Carvalho (2014), devido ao rápido desenvolvimento das tecnologias de informação e comunicação em associação ao avanço da Internet, houve a propagação das mídias sociais no turismo.

O acesso fácil através de aparelhos como notebooks, celulares, tabletes etc. faz com que as pessoas estejam conectadas o tempo todo ao mundo virtual, não observando o ambiente, seja em casa, na rua, ou até mesmo no local de trabalho. Com tanta facilidade, o acesso às redes sociais no ambiente de trabalho é uma realidade. Fato este que causa debate entre gestores das empresas e funcionários, quanto ao que seria apropriado com relação ao uso das redes sociais durante o horário de expediente. Dessa forma, este trabalho tem como objetivo analisar o uso da Internet e redes sociais no ambiente de trabalho, na perspectiva dos funcionários do setor hoteleiro da cidade de Natal, Rio Grande do Norte, Brasil. Considera-se que tal pesquisa tem importância ao passo em que se destaca o comportamento dos profissionais da hotelaria no que concerne ao uso das redes sociais. Além do mais, foi possível identificar o pensamento dos funcionários sobre sua produtividade e desenvolvimento frente o uso da Internet e das redes sociais no ambiente de trabalho. 


\title{
2 INTERNET E HOTELARIA
}

O segmento de hotelaria é um dos principais do turismo, uma vez que os meios de hospedagens são essenciais em qualquer destino turístico. Meios de hospedagem são:

\begin{abstract}
Os empreendimentos ou estabelecimentos, independentemente de sua forma de constituição, destinados a prestar serviços de alojamento temporário, ofertados em unidades de frequência individual e de uso exclusivo do hóspede, bem como outros serviços necessários aos usuários, denominados de serviços de hospedagem, mediante adoção de instrumento contratual, tácito ou expresso, e cobrança de diária (MINISTÉRIO DO TURISMO, 2014).
\end{abstract}

Com a globalização, surgem as novas tecnologias e aparatos que auxiliam nas atividades relacionadas ao setor hoteleiro. A Tecnologia da Informação e Comunicação traz mudanças significativas para o setor. Beal (2001) relata que o termo "Tecnologia da Informação" serve para designar o conjunto de recursos tecnológicos e computacionais para a geração e uso da informação. Oliveira (2000, p. 180) relata que "o acesso à informação para todos é uma forma de melhorar a qualidade pelo aprimoramento dos processos" onde todos que atuam numa empresa têm papel fundamental.

\begin{abstract}
A eficácia no uso da Tecnologia da Informação consiste em implantar e desenvolver sistemas que melhor se adaptem às necessidades dos usuários, da área de negócio e da empresa, que sejam consistentes com a estratégia global da corporação, que melhor contribuam para aperfeiçoar as atividades e as funções desempenhadas pelos usuários e ainda tragam ganhos em competitividade e produtividade para a empresa (LAURINDO, 2002, p. 33).
\end{abstract}

Para Stair (1998, p. 17), "um sistema de informação eficiente pode ter um grande impacto na estratégia coorporativa e no sucesso da organização”. Depende dos recursos utilizados e do uso correto de tais elementos.

O surgimento da internet e o desenvolvimento de programas específicos para cada tipo de setor, fez com que diversas atividades se tornassem mais ágeis e eficientes. A internet "é uma rede global de redes de computadores" (TURBAN; MCLEAN; WETHERBE, 2004, p. 122). Para Bissoli e Ambrizi (2002, p. 61), “A Internet é uma poderosa ferramenta de pesquisa em qualquer categoria de informação, e no caso de turismo motiva o usuário a utilizá-la cada vez mais", uma vez que através da internet as pessoas têm a oportunidade de conhecer e aprender sobre qualquer coisa, através 
principalmente do uso do World Wide Web (WWW), que "é um sistema com padrões aceitos internacionalmente para armazenar, recuperar, formatar e apresentar informações” (GUIMARÃES; BORGES, 2008, p. 27). Dessa forma, Turban, Mclean e Wetherbe (2004, p. 123) mencionam que "os recursos cada vez mais aperfeiçoados da internet permitem que as empresas dela se utilizem para a concretização dos mais diversos tipos de negócios". Os hotéis têm várias formas de utilizar a internet e as TIC's ao seu favor, sejam divulgando seus serviços através de redes sociais, sites etc.; seja com vendas online, e principalmente com investimentos em softwares e sistemas que auxiliam nas principais atividades realizadas por estes empreendimentos.

\footnotetext{
O setor de turismo é um grande incorporador de tecnologia, nos seus diversos segmentos, e o seu crescimento sempre depende da capacidade de inovação e do uso da tecnologia para melhoria da gestão, desenvolvimento de novos produtos, aperfeiçoamento da comunicação, otimização das experiências de viagens e personalização do atendimento (GUIMARẪES; BORGES, 2008, p. $10)$.
}

Silva e Mendes Filho (2013, p. 178) afirmam que "o turismo, a tecnologia de informação e comunicação e a internet formam um conjunto de parceria". Além das diversas possibilidades operacionais, os hotéis podem agregar a internet como forma de divulgação e como instrumento para melhorar seu relacionamento com clientes. $\mathrm{O}$ uso da internet se faz necessário para o bom desenvolvimento e desempenho da maioria das empresas. Santos e Santos (2014, p. 721) enfatizam que "novas tecnologias têm sido utilizadas a fim de atender às necessidades dos turistas, criando inúmeras oportunidades para empresas e destinos, seja na criação de novos produtos e serviços ou na agregação de valor aos já existentes". Guimarães e Borges (2008, p. 31) afirmam que "não dispor de um site na internet significa permanecer inacessível a milhares de consumidores do mundo todo". Pois uma ferramenta dessas pode trazer benefícios diversos quando bem utilizada.

\section{REDES SOCIAIS NA INTERNET}

A interação e as relações sociais adquiriram novas maneiras e significados com o surgimento da internet. Pois as pessoas podem se sentir mais próximas mesmo 
havendo distância física. "À medida que a conectividade aumenta o mundo diminui. É a capacidade coletiva de promover desenvolvimento por meio da desinstitucionalização da informação" (IBOPE, 2010). Segundo Guimarães e Borges (2008, p. 6) "as novas tecnologias de informação e comunicação e, notoriamente, a internet trouxeram a possibilidade inédita de comunicação instantânea e ubíqua, ou seja, disponível em toda a superfície do globo terrestre". As tecnologias digitais possuem um papel fundamental nas mudanças provadas na vida social.

De acordo com Barefoot e Szabo (2010, p. 28) "a internet se tornou um local comum em que o público responde as notícias, sugere histórias a serem exploradas e até mesmo realiza reportagens". É nesse contexto que surgem as chamadas redes sociais. Recuero (2009) aborda que uma rede social é definida como a união de dois elementos: atores (pessoas, instituições ou grupos; os nós da rede) e suas conexões (interações ou laços sociais). Cada vez mais as pessoas estão gastando tempo do seu dia interagindo com outras pessoas através das redes sociais. De acordo com o Ibope (2010) o acesso às redes sociais foi incorporado à rotina da maioria dos brasileiros.

As primeiras redes sociais surgiram por volta do ano de 1995 e foram crescendo a partir de 2002 com o surgimento do Fotolog e o Friendster, onde este primeiro consistia em publicações baseadas em fotografias. Nos anos seguintes foram surgindo outras redes como: LinkedIn, MySpace, Flickr, Orkut, Facebook, Twitter, Instagram, YouTube e WhatsApp, entre outras, cada uma com suas peculiaridades e formas de interação. "O Orkut foi a porta de entrada para a internet no Brasil" (IBOPE, 2010). Segundo Barefoot e Szabo (2010, p. 189) "no Facebook, uma boa parte de sua vida profissional é conectada ao seu perfil pessoal". As redes sociais fazem com que as pessoas se conectem com outros indivíduos, independente de fatores econômicos, financeiros, sociais e espaciais.

Cada pessoa tem seu objetivo ao adentrar em uma rede social. Enquanto algumas pessoas almejam apenas conhecer novos seres, outras buscam interação que desenvolva seu perfil profissional, além de compartilhar ideias, criar laços sociais e obter mais conhecimento sobre determinados assuntos. Cada Rede Social tem seu foco principal, as "redes sociais na Internet possuem elementos característicos, que servem de base para que a rede seja percebida e as informações a respeito dela sejam apreendidas" (RECUERO, 2009, p. 25). Pode-se destacar como redes sociais utilizadas no dia a dia 
(BAREFOOT; SZABO, 2010): LinkedIn, YouTube, Twitter, Facebook, Instagram e WhatsApp.

$\mathrm{O}$ uso frequente das redes sociais se dá, principalmente, pela facilidade em acessar a internet, uma vez que com as inovações tecnológicas surgiram diversos aparelhos e equipamentos para tal função. As pessoas se conectam através de computadores, tablets, notebooks, aparelhos de celulares, smartphones, entre outros, onde grande parte destes aparelhos pode ser conduzida pelos seus proprietários para qualquer lugar.

É importante destacar que cada vez mais existem pesquisas sobre mídias e redes sociais no cotidiano, e também tem-se discutido na academia sobre essa temática, havendo vários trabalhos acadêmicos na área do turismo que comprovam essa importância científica (MENDES FILHO, 2014; MENDES FILHO; CARVALHO, 2014; SILVA; MENDES FILHO, 2014).

\section{REDES SOCIAIS E O AMBIENTE DE TRABALHO}

O uso das redes sociais pelos brasileiros cresce. Seja para se divertir, conversar, conhecer pessoas novas ou até mesmo para procurar emprego, a utilização da internet se faz notória. E como existe uma grande facilidade de acesso à internet, as pessoas se conectam às redes sociais em qualquer lugar e a qualquer momento. $\mathrm{O}$ acesso que antes era restrito ao uso do computador pessoal em casa ou em lan houses, em horários específicos, passou a ser feito a todo o momento através de diversos dispositivos e aparelhos eletrônicos, destacando-se os aparelhos celulares e smartphones. Tais aparelhos "oferecem inúmeras possibilidades por meio de troca de informações digitais, incluindo textos, imagens, sons e vídeos" (SANTOS; SANTOS, 2014, p. 718).

Roberto (2009, p. 41) comenta que "as redes sociais mudaram as estratégias de comunicação interna e externa, o que antes era mantido com certa distância, hoje se torna muito mais próximo". Neste sentido, os gestores de muitas empresas se interrogam e discutem sobre o uso das redes sociais no ambiente de trabalho e, principalmente, em horário de expediente. "Nas organizações brasileiras não há 
consenso de opiniões nem uniformidade de padrões de uso das redes sociais" (CARVALHO; SILVA; OLIVEIRA, 2013, p. 8).

A tecnologia da informação se faz presente em quase todas as organizações. Segundo Oliveira (2000, p. 180) "a informática é a ferramenta que melhor permite trabalhar a informação, facilitando o armazenamento, processamento e recuperação dela, tudo isso com alta velocidade”. Mas para tanto é preciso que as pessoas saibam manusear esta ferramenta. "Há necessidade de profissionais qualificados, capazes de entender a informação e que tenham disposição em aprimorar seu conhecimento e aplicá-lo na melhoria de seu trabalho" (OLIVEIRA, 2000, p. 180). O ambiente de trabalho, com aparatos tecnológicos, propicia a utilização da internet pelos profissionais que atuam nas empresas. Stair (1998, p. 40) aborda que "as organizações usam sistemas de informação para darem apoio às suas metas".

As empresas utilizam distintos tipos de tecnologia da informação. A maioria delas são adeptas do uso de redes sociais, onde possuem perfis empresariais que servem de comércio eletrônico e divulgação da organização e de seus serviços e produtos. Para Stair (1998, p. 175) "as redes têm sido um instrumento chave no auxílio às empresas para enviar informação imediata à pessoa certa, da forma certa”. Mas quando se trata do uso de redes sociais pelos funcionários das empresas, existe uma preocupação com possíveis problemas que isto pode ocasionar. Algumas empresas proíbem que seus funcionários acessem a internet no local de trabalho, pois acreditam que tal ato faz com que a produtividade do colaborador diminua. Mas acaba sendo quase impossível intervir sobre tal fato, pois as pessoas se conectam às redes sociais, geralmente, através de aparelhos celulares e/ou outros aparelhos tecnológicos de uso pessoal.

\footnotetext{
Existem empresas recorrendo a um software especial que monitora o tempo gasto na internet, por funcionário e site acessado. O objetivo do procedimento é eliminar o abuso no acesso durante as horas de trabalho e o acesso a sites "indecentes" (TURBAN; MCLEAN; WETHERBE, 2004, p. 146).
}

Podem-se relatar três maneiras dos gestores das empresas agirem no que concerne ao uso da internet e das redes sociais no ambiente de trabalho: liberar o acesso livre, permitir o acesso em horários específicos ou, fechar e proibir totalmente o acesso. Cada uma dessas ações pode gerar pontos positivos e negativos, depende da maneira como isto é posto aos funcionários. Um fato que facilita ainda mais o uso das redes 
sociais no ambiente de trabalho é que muitas empresas liberam o acesso a internet através de wifi para seus clientes e, mesmo que alguns estabelecimentos possuam senhas para liberar a conexão, tal informação é facilmente obtida.

\section{METODOLOGIA}

Para realizar este trabalho foi utilizada a pesquisa do tipo exploratório-descritiva, onde foram estabelecidos critérios, métodos e técnicas para sua elaboração, bem como se realizou o estudo, a análise, o registro e a interpretação dos fatos colhidos. Gil (1999) aborda que a pesquisa exploratória é desenvolvida no sentido de acomodar uma visão geral acerca de certo fato. Com relação a pesquisa descritiva, Gil (1999) relata que ela tem como principal objetivo descrever características de determinada população. Em se tratando de fontes de pesquisas, foram utilizados materiais bibliográficos e acervos documentais de diversas organizações, como: IBOPE, Ministério do Turismo etc. Assim foi empregada a pesquisa de campo, onde o alvo foi o dos hotéis atuantes na cidade de Natal/RN (Brasil). A abordagem foi do tipo quali-quantitativa, uma vez que foi realizada entrevista com perguntas abertas e fechadas.

Como população da pesquisa foi utilizada a dos funcionários que usavam redes sociais no ambiente de trabalho, que atuavam em hotéis de Natal, considerando uma amostragem do tipo não probabilística por acessibilidade, que segundo Marotti et al (2008) tal amostragem é destituída de qualquer rigor estatístico. O pesquisador escolhe os elementos a que tem acesso, aceitando que estes possam representar um universo. Foram realizadas entrevistas online através da ferramenta do Google Drive, bem como entrevistas presenciais através de formulários impressos. A coleta dos dados ocorreu entre os dias 22 de abril e 19 de maio de 2014, totalizando 52 funcionários respondentes, atingindo 9 hotéis. A análise dos resultados se deu através da análise de conteúdo, de acordo com Olabuenaga e Ispizúa (1989, p. 2), “a análise de conteúdo é uma técnica para ler e interpretar o conteúdo de toda classe de documentos, que analisados adequadamente nos abrem as portas ao conhecimento de aspectos e fenômenos da vida social de outro modo inacessíveis". Dessa forma foi possível obter os resultados a serem apresentados. 


\section{UTILIZAÇÃO E INFLUÊNCIA DAS REDES SOCIAIS NO AMBIENTE DE TRABALHO}

O acesso fácil à internet e às várias redes sociais existentes faz com que diversas pessoas as utilizem em qualquer lugar ou horário. Na pesquisa foram entrevistadas 52 pessoas que estavam atuando em nove hotéis pertencentes à rede hoteleira da cidade de Natal, Rio Grande do Norte.

QUADRO 2 - PERFIL DOS ENTREVISTADOS

\begin{tabular}{|c|c|c|c|c|c|}
\hline \multicolumn{7}{|c|}{ PERFIL DOS ENTREVISTADOS } \\
\hline GENERO & QTD & FAIXA ETÁRIA & QTD & ESCOLARIDADE & QTD \\
\hline Masculino & 23 & 16 a 25 & 24 & Ensino Médio & 26 \\
\hline & & 26 a 35 & 19 & Ensino Superior & 20 \\
\cline { 3 - 6 } Feminino & \multirow{2}{*}{29} & 36 a 45 & 7 & Pós-graduação & 6 \\
\cline { 3 - 4 } & & 46 a 55 & 2 & & \\
\hline
\end{tabular}

Fonte: Dados da pesquisa, 2014

Dos entrevistados, 29 foram do gênero feminino e 23 do gênero masculino. A maioria deles foi considerada jovem e adulta entre 16 e 45 anos. No que concerne à escolaridade, se considerar as funções, foi possível identificar que a maioria das pessoas que possuía ensino médio atuava em funções operacionais. Com relação à função exercida pelos entrevistados, os cargos variaram e se situaram na maioria dos níveis hierárquicos: auxiliar financeiro (1), auxiliar de Departamento Pessoal (1), aprendiz (6), assistente financeiro (3), frigobeiro (1), gerente front office (1), assistente de vendas (1), auxiliar de reservas (1), recepcionista (8), gerente (2), auxiliar de controladoria (1), controller financeiro (1), auxiliar de serviços gerais (5), camareira (13), assistente administrativo (3), assistente de eventos (2) e porteiro (2). Dessa forma identificou-se que foi possível atingir vários níveis hierárquicos.

A utilização da internet por parte dos funcionários de uma organização é quase inevitável, pois geralmente tais pessoas trabalham com ferramentas e informações tecnológicas. Para Turban, Mclean e Wetherbe (2004, p. 146) "há também funcionários que podem se sentir tentados a navegar em interesses particulares em horários de trabalho". Diversas pessoas utilizam a internet e suas ferramentas tanto no âmbito pessoal como profissional, com ou sem o consentimento de seus gestores. Os resultados da pesquisa apresentaram que 49 pessoas acessavam a internet no local de trabalho e apenas 3 não tinham esse costume. 
É raro encontrar alguma empresa em que não se utiliza da tecnologia da informação para obter alguma vantagem. "Para o sucesso de toda e qualquer empresa, ela precisa ter acesso à informação correta, relevante e no momento certo" (TURBAN; MCLEAN; WETHERBE, 2004, p. 146). Um fator abordado na pesquisa foi sobre a liberação ou não deste acesso pelos hotéis onde estes funcionários trabalhavam, uma vez que com o avanço da tecnologia muitas empresas também passaram a utilizar a internet e as redes sociais para divulgar e vender seus produtos e serviços. A pesquisa revelou que a maioria (sete) dos hotéis liberava o acesso, mesmo que em horários restritos.

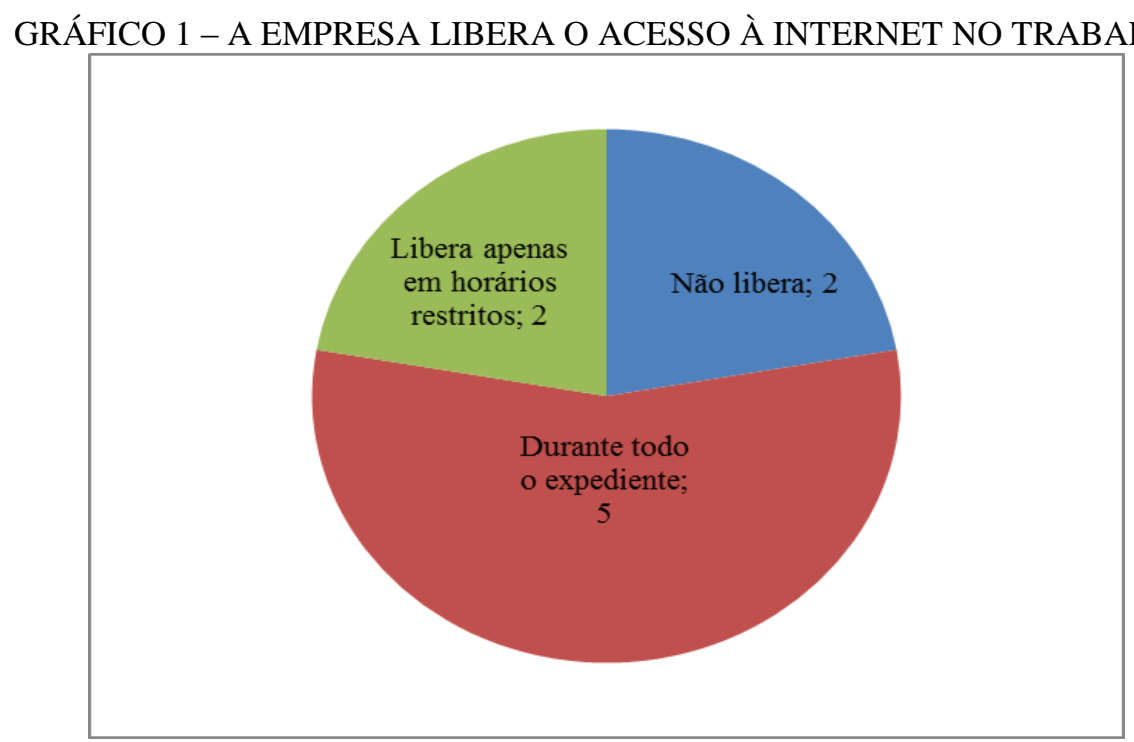

Fonte: Dados da pesquisa, 2014.

Compete informar que a navegação em sites e a utilização de ferramentas virtuais para fins pessoais podem ser restringidas ou mesmo proibidas pelo empregador, através de seu poder diretivo e regulamentar, principalmente quando isto for realizado através de aparelhos pertencentes à empresa. Segundo Santos e Santos (2014, p. 718) "dentre as diversas novas tecnologias de comunicação que têm alterado a realidade do turismo, uma que merece grande destaque é a telefonia móvel". Quando perguntados sobre com quais aparelhos costumavam acessar a internet, a maioria mencionou utilizar seu celular/smartphone. Das 52 entrevistas, 32 pessoas responderam utilizar computadores, tabletes e celulares: 


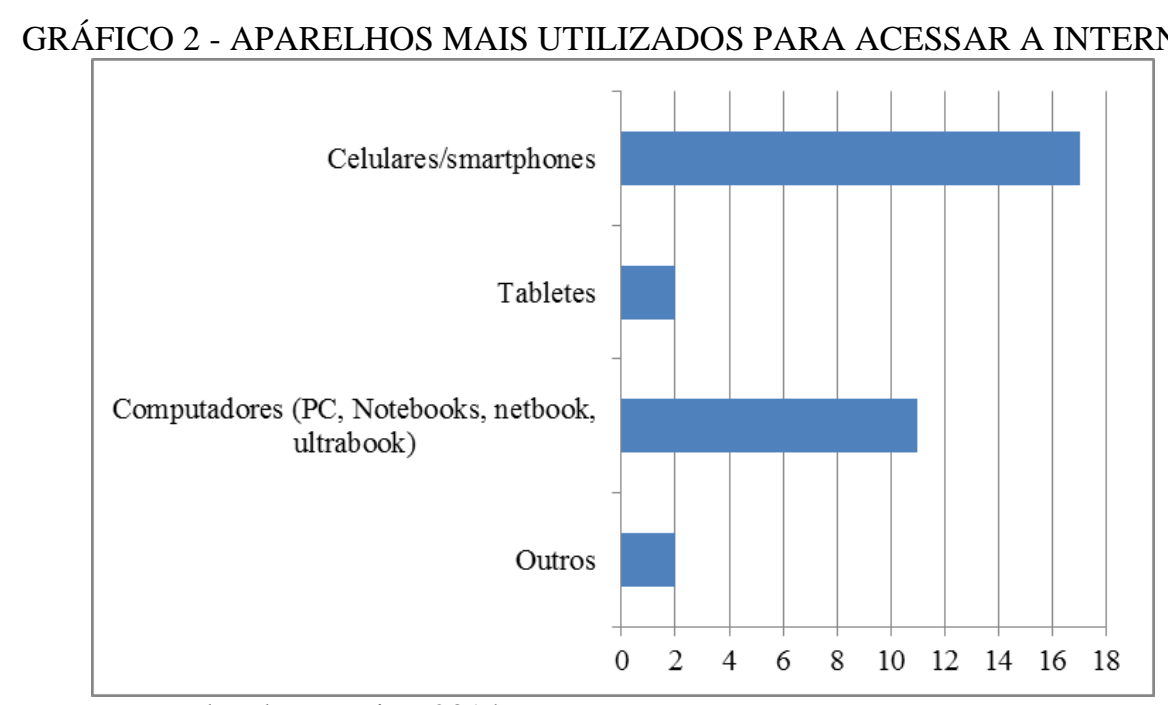

Fonte: Dados da pesquisa, 2014.

Outras 20 pessoas responderam que utilizavam mais de um desses aparelhos, uma vez que algumas utilizavam aparelhos celulares quando estavam no local de trabalho e o computador em casa, ou vice versa. Considera-se ser perceptível que as pessoas estão cada vez mais buscando conhecimento e interação através da internet. Guimarães e Borges (2008, p. 8) alertam que "na era da informação, a maior e mais duradoura vantagem competitiva vem do conhecimento". Então os gestores das empresas devem atentar a como e para que esteja distribuindo informação e capacitação aos seus funcionários.

Com relação ao tempo atribuído ao uso da internet e de redes sociais, a pesquisa revelou que os funcionários estavam utilizando boa parte do seu dia para usufruir de tais recursos, pelo menos duas horas diárias, como se mostra no gráfico abaixo.

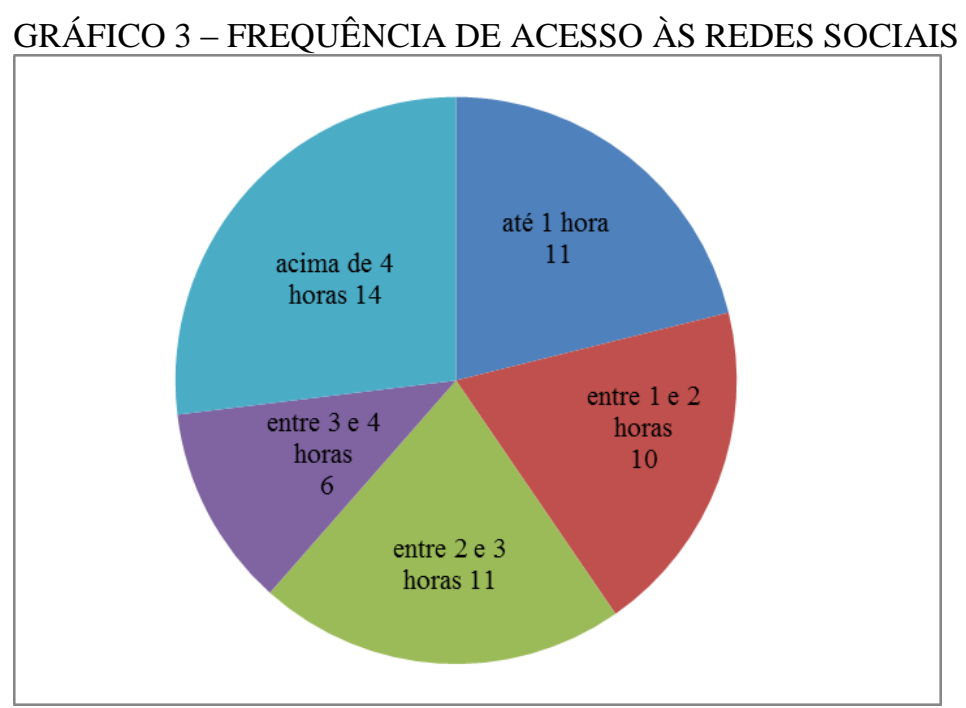

Fonte: Dados da pesquisa, 2014. 
O uso das redes sociais sobrepujou não somente o público jovem, mas também todas as faixas etárias de profissionais. Cada vez mais as pessoas estão aderindo às variadas formas de se comunicar e conectar com os demais. Redes sociais como Facebook, Instagram, Twitter entre outras fazem parte do cotidiano das pessoas. Barefoot e Szabo (2010, p. 189) relatam que "é importante entender que o Facebook pode se tornar um equilíbrio delicado entre sua abertura pessoal e suas atividades profissionais". Pois dependendo da maneira como se utiliza tal ferramenta, pode causar impactos positivos ou negativos tanto para o profissional como para a empresa. Os pesquisados indicaram as redes sociais mais utilizadas por eles, resultando nos seguintes dados: Facebook (19), WatsApp (17), Instagram (8), Twitter (3), Linkedin (3) e outros (2). Vale informar que "o corpo empresarial prioriza aquelas redes que têm conteúdo e perfis comerciais para apoio e divulgação de pessoal técnico especializado, como é o caso, por exemplo, da Linkedln" (CARVALHO; SILVA; OLIVEIRA, 2013, p. 10) que não foi tão utilizado pelos respondentes.

Uma pergunta pertinente foi sobre qual o principal motivo que levavam as pessoas a acessarem as redes sociais. A maioria dos pesquisados (37 no total) respondeu que fazia isso para principalmente trocar mensagens, se divertir e se informar. Assim, percebeu-se que existiu a busca pela interação social, que as pessoas procuravam manter contato umas com as outras de forma cada vez mais dinâmica e instantânea.

GRÁFICO 4 - PRINCIPAL MOTIVO DE ACESSO ÀS REDES SOCIAIS.

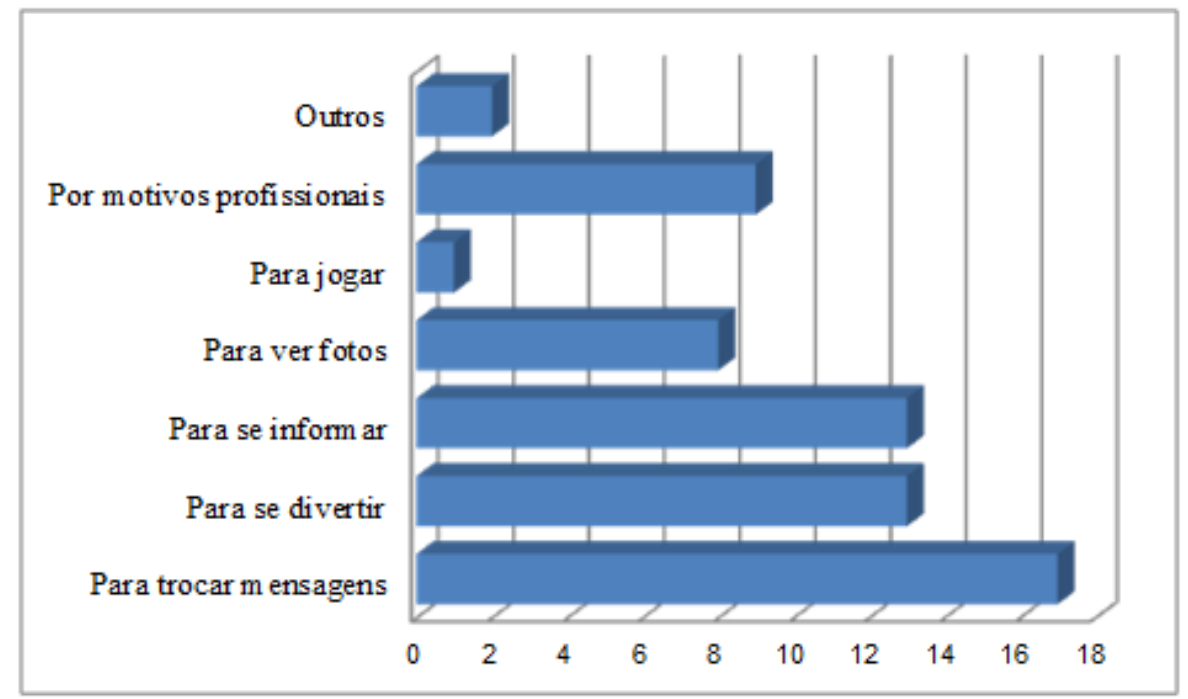

Fonte: Dados da pesquisa, 2014. 
No que concerne à vivência profissional dos entrevistados, foi perguntado se costumavam realizar suas atividades diárias e utilizar as Redes Sociais ao mesmo tempo, onde 40 pessoas responderam que sim e, 12 pessoas disseram que não. Stair (1998, p. 21) menciona que "nossa sociedade está se tornando dependente da tecnologia de informação". Foi possível observar esta realidade no resultado desta pesquisa, onde as pessoas não se preocupavam se estavam no local de trabalho realizando suas atividades e obrigações, mas estavam conectadas e atentas a tudo que acontecia no meio virtual.

Mas o uso exagerado dessas redes sociais pode gerar distração e até mesmo perda de tempo nas atividades profissionais. Com relação ao desempenho das atividades diárias por parte dos pesquisados, foi perguntado se o fato de acessar as redes sociais em horário de trabalho não as comprometia profissionalmente. Algumas falas foram destacadas, conforme segue:

"Um pouco, depende do trabalho que você esteja exercendo. Quando é algo que requer muita atenção, não tem como. Fora isso, pelo menos pra mim não tem problema". (Feminino, assistente financeiro).

"Não. Os deveres podem ser aliados à diversão". (Masculino, gerente front office).

"Não irá comprometer o desempenho, porém pra tudo tem sua hora e algumas tarefas no trabalho exigem máxima atenção". (Feminino, recepcionista).

"Não, desde que o uso neste horário seja voltado para o âmbito profissional, tendo em vista que alguns profissionais têm contato com clientes e fornecedores por meio da comunicação via rede social”. (Masculino, controller financeiro).

"Sim, por tirar a sua atenção de suas atribuições". (Masculino, auxiliar de controladoria).

"Sim, tudo que é paralelo ao serviço acaba atrapalhando. Tira a atenção, não tem como não esquecer o que estava fazendo". (Feminino, assistente financeiro).

"Sim. No meu setor com tem muitas atividades a ser realizadas, acessar as redes sociais compromete sem dúvida o desempenho, já que o tempo é curto pra realizar todas as tarefas, parar o trabalho para fazer outra coisa, com certeza diminuir o desempenho". (Feminino, auxiliar de reservas). 
A partir dos comentários foi possível perceber que existiu uma divisão de opiniões, onde algumas pessoas não viam nenhum problema em conciliar as atividades profissionais ao uso das redes sociais no ambiente de trabalho. Mas outra parte dos pesquisados manifestou acreditar que estar conectado em tais redes e realizar suas atividades ao mesmo tempo não era uma boa ideia, pois tirava a atenção e o foco dos exercícios diários. Existiram aqueles que relataram que dependia do horário e de qual tarefa estaria executando.

O uso de redes sociais e ferramentas da internet pelas empresas se tornaram algo importante e eficaz. Muitas organizações apresentam, divulgam e vendem seus produtos e serviços através destes instrumentos e passaram a obter lucros e atingindo um número maior de consumidores ativos e passivos. "Empresas que permanecem competitivas são aquelas que reconhecem o valor das informações e estruturam suas atividades e sistemas de informação de forma a maximizar esses recursos" (STAIR, 1998, p. 384). Considerando tal afirmativa, foi perguntado aos respondentes se o hotel onde eles atuavam fazia uso de alguma rede social para arrecadar vantagens competitivas e aumentar seus lucros, e a partir do depoimento dos entrevistados obteve-se que dos nove hotéis apenas dois não utilizavam esse recurso. Os outros sete possuíam perfil nas principais redes sociais existentes e divulgavam diariamente seus serviços e produtos.

Os gestores das empresas estão buscando identificar seus novos funcionários através também dos perfis das redes sociais que eles possuem. Muitas pessoas perdem a oportunidade de trabalhar em uma organização pelo mau uso destas ferramentas. Mas existem pessoas que conseguem se destacar justamente por saber extrair proveitos das mesmas redes sociais. Sobre tal fato, foi perguntado se o uso das Redes Sociais poderia ajudar no crescimento profissional. Algumas respostas foram destacadas:

"Sim. Networking e troca de experiências com pessoas do mesmo ramo". (Masculino, gerente front office).

"Depende. Não são todos que sabem fazer bom uso. Mas se procurar páginas/aplicativos interessantes, é possível se dar bem profissionalmente”. (Feminino, assistente financeiro).

"Sim. As redes sociais hoje em dia são a principal fonte de informações para ficarmos atualizados no nosso dia a dia”. (Masculino, recepcionista). 
"Não. Acho eu que de forma alguma isso traz benefícios pra mim. A gente faz porque está viciado, queira ou não é um vício! Mas sem ele, seria bem melhor”. (Feminino, camareira).

Sobre tal questionamento as opiniões foram bem divididas. Muitas pessoas não consideraram que o uso das redes sociais pudesse trazer benefícios profissionais. Vale ressaltar que a maioria das pessoas que respondeu negativamente, era de profissionais de setores operacionais, a maioria camareiras e auxiliares de serviços gerais, que estavam exercendo atividades imediatas e que não permitiam muitos espaços de tempo para fazer uso de tais ferramentas. Mas é preciso expor que o bom uso desses mecanismos pode gerar melhorias profissionais, uma vez que existe uma gama de informações úteis na internet e que pode aprimorar o conhecimento e a qualificação dos internautas.

\section{CONSIDERAÇÕES FINAIS}

A realização deste trabalho trouxe ainda mais a certeza de que a tecnologia da informação, bem como a internet e as redes sociais são uma realidade e que não podem ser deixadas de lado, seja por parte dos gestores das empresas ou dos funcionários que atuam nelas. A popularização e o fácil acesso à internet fizeram com que as pessoas estejam diária e instantaneamente conectadas e atentas ao que acontece no mundo.

O surgimento das redes sociais fez com que as pessoas estejam em contato direto com quem desejar. Mas o uso exagerado de tais ferramentas pode consumir muito tempo das pessoas, fazendo com que estas deixem de realizar suas atividades diárias. Considerando o aspecto profissional, verificou-se que os funcionários atuantes nos hotéis da cidade do Natal/RN acessavam a Internet e as redes sociais diariamente e quase sempre fazendo isso em horário e no ambiente de trabalho. Mas tal prática pode acarretar em danos para o funcionário caso a empresa não permita o acesso livre às redes sociais. Para que não haja problemas o funcionário pode adotar algumas medidas como: delimitar horários para acessar sem que precise deixar de cumprir com suas obrigações; ser seletivo, não se conectar a todo tipo de rede social no ambiente de trabalho; refletir sobre seu emprego, se o acesso a tais ferramentas não está trazendo 
prejuízos ou pode se tornar um problema mais adiante; e, conter a ansiedade, procurar não demonstrar nem falar muito sobre tais assuntos, principalmente diante de seus superiores.

Em se tratando de gestores de uma empresa, os mesmos têm direito de não liberar o acesso à internet, caso acreditem que tal fato prejudica o desempenho das atividades dos funcionários. Mas a tecnologia da informação se faz presente em praticamente todos os setores das organizações e seu uso adequado pode maximizar lucros e minimizar custos. Além do mais no que concerne a utilização de redes sociais, os gestores de muitas empresas estão aproveitando para divulgar e comercializar seus produtos e serviços através das mesmas. Muitos hotéis estão investindo em profissionais qualificados para desenvolver perfis em redes sociais buscando atingir o máximo de pessoas que possam se tornar clientes. Assim os hotéis podem utilizar as redes sociais para atuar como uma central de atendimento ao cliente, mantendo contato direto com o consumidor. Além do mais o investimento nesse tipo de publicidade pode ser considerado barato e eficaz.

A pesquisa apresentou algumas limitações representativas, como por exemplo: sua realização abarcou apenas nove hotéis da cidade de Natal, considerando que tal cidade é considerada turística e possui um grande número de estabelecimentos de hospedagem, sua abrangência poderia ter sido maior. Além do mais, foram percebidos que alguns funcionários apresentaram certo desconforto e receio em responder às perguntas, se acobardando serem penalizados pelos gestores caso os mesmos não gostassem das respostas aferidas. Contudo, tais limitações podem ser apaziguadas com futuros estudos mais qualitativos e/ou quantitativos aprofundando-se mais sobre o assunto.

Portanto, pode-se concluir que o uso da Internet e das redes sociais no ambiente de trabalho é algo que já faz parte da realidade dos funcionários que estavam atuando nos nove hotéis pesquisados na cidade de Natal, Rio Grande do Norte e que, para tais empresas, manter-se conectadas também às redes sociais se torna uma ferramenta útil para conquistar outros clientes. Dessa forma, os gestores dos hotéis necessitam valer-se de seus benefícios, suas regalias e instruir-se cada vez mais na utilização das mesmas, pois, os gestores das empresas competitivas e que almejam solidez e lucros devem saber 
atuar dentro e fora da Internet, angariando para si todas as benfeitorias e vantagens que a tecnologia da informação oferece.

\section{REFERÊNCIAS}

BAREFOOT, D; SZABO, J. Manual de marketing em mídias sociais. São Paulo: Novatec Editora, 2010.

BEAL, A. Introdução à gestão de Tecnologia da Informação. 2001. Disponível em: <http://2beal.org/ti/manuais/GTI_INTRO.PDF>. Acesso em: 07/05/2014.

BISSOLI, M. A.; AMBRIZI, M. Planejamento turístico municipal com suporte em sistemas de informação. 3. ed. São Paulo: Futura, 2002.

BOLETINES PANDALABS. Redes Sociales en el punto de mira, 2008. Disponível em: <http://www.pandasecurity.com/img/enc/Red_Soc_punto_mira.pdf >. Acesso em: $17 / 04 / 2014$.

CARVAlHO, A. V.; SILVA, D. M. S.; OLIVEIRA, M. R. S. Redes Sociais no ambiente profissional: fator de produtividade ou de distração? Múltiplos olhares em ciência da informação, v. 3, n. 2, p. 1-13, 2013.

GIL, A C. Métodos e técnicas da pesquisa social. 5. ed. São Paulo: Atlas, 1999.

GUIMARÃES, A S.; BORGES, M P. E-turismo: internet e negócios do turismo. São Paulo: Cengage Learning, 2008.

IBOPE - Instituto Brasileiro de Opinião e Estatística. Many-to-many: O fenômeno das redes sociais no Brasil (2010). Disponível em: <http://www4.ibope.com.br/download/Redes_Sociais.pdf>. Acesso em: 01/04/2014.

LAURINDO, F. J. B. Tecnologia da informação. São Paulo: Futura, 2002.

LOBIANCO, M. M. L.; RAMOS, A. S. M. Uso da internet no setor de hotelaria de Recife-PE. RAE-Eletrônica, v. 3, n. 2, p. 1-19, 2004.

MAROTTI, J.; GALHARDO, A. P. M.; FURUYAMA, R. J.; PIGOZZO, M. N.; CAMPOS, T. N.; LAGANÁ, D.C. Amostragem em pesquisa clínica: tamanho da amostra. Revista de Odontologia da Universidade Cidade de São Paulo, v. 20, n. 2, p. 186-194, 2008. 
MENDES FILHO, L. Empowerment in the context of User-Generated Content in the Travel Industry: A research model proposal. El Periplo Sustentable, v. 27, p. 4-20, 2014.

MENDES FILHO, L.; CARVALHO, M. S. D. Factores que influyen en el uso del contenido generado por el usuario en internet: Un estudio preliminar con viajeros brasileños. Estudios y Perspectivas en Turismo, v. 23, n. 3, p. 607-625, 2014.

MENDES FILHO, L.; CORREA, C. H. W.; MANGUEIRA, M. R. Online Travel Reviews on Mobile Applications when making travel plans: Uses and Gratifications perspectives. e-Review of Tourism Research, v. 6, p. 1-5, 2015.

MINISTÉRIO DO TURISMO. Cartilha de orientação básica - HOTEL. Disponível em:

<http://www.turismo.gov.br/export/sites/default/turismo/o_ministerio/publicacoes/down loads_publicacoes/2_CARTILHA_HOTEL.pdf>. Acesso em: 01/05/2014.

OLABUENAGA, J. I. R.; ISPIZUA, M. A. La descodificacion de la vida cotidiana: metodos de investigacion cualitativa. Bilbao: Universidad de Deusto, 1989.

OLIVEIRA, J. F. Sistemas de informação: um enfoque gerencial inserido no contexto empresarial e tecnológico. 3 ed. São Paulo: Érica, 2000.

PEW RESEARCH CENTER. Emerging Nations Embrace Internet, Mobile Technology (2013). Disponível em: <http://www.pewglobal.org/2014/02/13/emergingnations-embrace-internet-mobile-technology>. Acesso em: 21/04/2014.

RECUERO, R. Redes Sociais na Internet. Porto Alegre: Sulina, 2009.

ROBERTO, L M. A influencia das redes sociais na comunicação organizacional. 2009. Monografia (Graduação em comunicação social), UNINOVE, São Paulo - 2009. Disponível em: <http://www.aberje.com.br/monografias/redessociais_comorganiz.pdf>. Acesso em: 19.08.2015.

SANTOS, J. A.; SANTOS, G. E. Uso de smartphones em viagens de turismo: análise do comportamento do mercado paulistano. Turismo \& Sociedade, v. 7, n. 4, p. 716$732,2014$.

SILVA, M. M.; MENDES FILHO, L. Intenção de uso de comentários de viagem online na escolha de um meio de hospedagem: Fatores influenciadores. Revista Brasileira de Pesquisa em Turismo, v. 8, n. 3, p. 419-434, 2014.

SILVA, D. S.; MENDES FILHO, L. Uma análise preliminar do uso de comentários na internet na escolha de um destino de viagem. Turismo: Estudos \& Práticas (RTEP/UERN), v. 2, n. 2, p. 174-195, 2013.

STAIR, R M. Princípios de sistemas de informação: uma abordagem gerencial. 2. ed. Rio de Janeiro: LTC, 1998. 
TURBAN, E.; MCLEAN, E.; WETHERBE, J. Tecnologia da informação para gestão: Transformando os negócios na economia digital. 3. ed. Porto Alegre: Bookman, 2004.

Recebido em: 18-12-2014.

Aprovado em: 17-01-2015. 